\title{
CAPACIDADE DE USO E APTIDÃO AGRÍCOLA DAS TERRAS DE PROPRIEDADES RURAIS LOCALIZADAS NA BACIA HIIDOGRÁFICA DO ARROIO ${ }^{1}$ PELOTAS $^{2}$
}

\author{
Luis Eduardo Akiyoshi Sanches Suzuki ${ }^{3}$ \\ William Roger da Silva Almeida \\ Rodrigo de Lima do Amaral \\ Mariana Fernandes Ramos \\ Moisés Ortemar Rehbein \\ Roberta Jeske Kunde
}

\begin{abstract}
RESUMO
O uso intenso do solo e a não adoção de práticas conservacionistas resulta em sua degradação e impactos ao ambiente. Nesse sentido, o presente estudo teve como objetivo avaliar a capacidade de uso e a aptidão agrícola das terras de algumas propriedades rurais da Bacia Hidrográfica do Arroio Pelotas, localizadas no município de Pelotas/RS, utilizando as metodologias propostas, respectivamente, por Lepsch et al. (1991) e Schneider, Giasson e Klamt (2007). Para isso, foram avaliadas três propriedades rurais com pastagem, uma com lavoura e cinco com pomares de pêssego de diferentes idades (0, 2, 6, 8 e 12 anos). A partir dos resultados levantados, verifica-se que as áreas apresentam limitações quanto a capacidade de uso e aptidão agrícola, especialmente relacionadas à pouca profundidade efetiva do solo e, aos riscos de erosão associados à declividade e à textura média na camada superficial do solo. Apesar das limitações quanto ao uso destas áreas, a pastagem e a fruticultura são usos menos intensos de exploração do solo do que as culturas anuais, contudo, ainda se tornam necessárias a implementação de novas práticas conservacionistas do solo e da água ou manutenção daquelas já utilizadas.
\end{abstract}

Palavras-chave: Degradação do solo. Práticas conservacionistas do solo. Limitações de uso das terras.

\section{CAPACITY OF USE AND AGRICULTURAL APTITUDE OF LAND OF RURAL PROPERTIES LOCATED IN THE PELOTAS RIVER HYDROGRAPHIC BASIN}

\begin{abstract}
The intense use of the soil and the failure to adopt conservationist practices, leads to its degradation and impacts on the environment. In this sense, the present study aimed to evaluate the capacity of use and the agricultural aptitude of the lands of some rural properties of the Hydrographic Basin of Arroio Pelotas, located in the municipality of Pelotas/RS, using the

\footnotetext{
${ }^{1}$ Este trabalho é parte do Trabalho de Conclusão de Curso do segundo autor, intitulado "Capacidade de uso e aptidão agrícola das terras em propriedades rurais localizadas na Bacia Hidrográfica do Arroio Pelotas", apresentado no ano de 2016 ao curso de graduação em Engenharia Hídrica da Universidade Federal de Pelotas.

${ }^{2}$ Como citar este artigo: SUZUKI, L. E. A. S. et al. Capacidade de uso e aptidão agrícola das terras de propriedades rurais localizadas na bacia hidrográfica do Arroio Pelotas. ForScience, Formiga, v. 9, n. 1, e00873, jan./jun. 2021. DOI: 10.29069/forscience.2021v9n1.e873.

${ }_{3}^{3}$ Autor para correspondência: Luis Eduardo Akiyoshi Sanches Suzuki, e-mail: dusuzuki@ gmail.com.
} 
methodologies proposed, respectively, by Lepsch et al. (1991) and Schneider, Giasson e Klamt (2007). For this, were evaluated three rural properties with pasture, one with annual crops and five with peach orchards of different ages $(0,2,6,8$ and 12 years). From the results obtained, the areas have limitations in terms of their use capacity and agricultural aptitude, especially related to the little effective depth of the soil and the risks of erosion associated with the slope and the medium texture in the superficial layer of the soil. Despite the limitations on the use of these areas, pasture and orchards are less intense uses of soil than annual crops, however, it is still necessary to implement new soil and water conservation practices or maintain those already used.

Keywords: Soil degradation. Soil conservation practices. Landuse limitations.

\section{INTRODUÇÃO}

O uso intensivo do solo, sem considerar critérios técnicos adequados, como a sua capacidade ou aptidão de uso e sem a implementação de recursos adequados de conservação do solo e da água, pode levar a impactos negativos ao solo e ao ambiente. Com isso, há necessidade de implementação de técnicas de manejo do solo que sejam adequadas e evitem ou minimizem sua degradação e do ambiente. Nesse sentido, a avaliação da capacidade de uso das terras ou de sua aptidão agrícola pode auxiliar no uso racional do solo e dentro de sua capacidade ou aptidão. Essas ações deveriam ser implementadas em nível de bacias hidrográficas, considerando sua magnitude e importância nos processos locais, regionais e globais.

Para manter a capacidade produtiva dos solos e evitar o seu acelerado esgotamento, especialmente em países tropicais e subtropicais como o Brasil, que estão mais expostos às intensas pluviosidades, faz-se necessário realizar o manejo agrícola baseado em condições definidas pelos elementos físicos da paisagem, as potencialidades do solo, do clima e do relevo da região (CUNHA; PINTON, 2012).

De acordo com D’Agostini e Schlindwein (1998) um sistema de classificação ideal de avaliação da capacidade de uso das terras precisa levar em consideração suas fragilidades e potencialidades a partir de critérios estabelecidos pelas experiências dos produtores locais e representar a realidade local, daí a importância de um sistema de classificação do uso das terras adequado às realidades e diversidades de cada região.

Lepsch et al. (1991) apresentam uma metodologia de avaliação da capacidade de uso das terras que indica o grau de intensidade de cultivo que se pode aplicar em uma determinada área sem que o solo sofra diminuição da sua produtividade por efeito de erosão, ou seja, tem o propósito de definir a máxima capacidade de uso sem que ocorra sua degradação. A metodologia tem como base ações conservacionistas e se aplica em propriedades rurais ou pequenas bacias hidrográficas. 
Posteriormente, Ramalho Filho e Beek (1995) propuseram um método que apresenta diferentes níveis de manejo, podendo passar por ajustes dependendo da exigência do estudo e, consiste basicamente em uma avaliação física da terra, baseada na sua qualidade e em níveis de manejo para diferentes usos.

Schneider, Giasson e Klamt (2007) propõem uma metodologia que indica o nível de intensidade ao que o solo pode ser submetido, auxiliando no diagnóstico da propriedade e indicando a sua aptidão agrícola. Também servindo de ferramenta na indicação da adoção de práticas conservacionistas para cada área. Dentre as metodologias apresentadas, esta é a mais recente.

Diante da relevância do tema, não apenas para a produção agrícola, a Companhia Estadual de Energia Elétrica - Geração e Transmissão (COMPANHIA ESTADUAL DE ENERGIA ELÉTRICA - GERAÇÃO E TRANSMISSÃO, s.d.) - Rio Grande do Sul possui estudos sobre a aptidão agrícola do solo junto às margens dos reservatórios da companhia com o objetivo de orientar os proprietários destas áreas sobre a melhor forma de utilizá-las, levando em consideração a legislação ambiental e os usos já consolidados.

Em reservatórios artificiais construídos especialmente com a finalidade de geração de energia, o estudo do entorno do reservatório é fundamental, especialmente quando o objetivo é evitar o assoreamento acelerado causado pelo uso do solo, o que implica diretamente na vida útil do reservatório e, consequentemente, na geração de energia.

As metodologias apresentadas por Lepsch et al. (1991) e Schneider, Giasson e Klamt (2007), são utilizadas no desenvolvimento deste estudo, em um levantamento simplificado das características da terra, buscando identificar e mapear as variáveis que possam impor limitações ao uso agrícola.

Estudos a nível de propriedades rurais são importantes, seja para aplicação de recomendações da pesquisa a nível de agricultor ou, para atender suas demandas e necessidades. Espera-se com este trabalho, contribuir com ferramentas de diagnóstico do uso do solo, auxiliando agricultores, extensionistas e gestores no uso de práticas conservacionistas do solo e da água, bem como nortear pesquisas na bacia hidrográfica em questão.

O presente estudo foi realizado em propriedades rurais localizadas na zona rural do Município de Pelotas, que é um importante polo produtor de alimentos e gerador de renda. Devido à importância do solo para manutenção da produtividade e dos processos ambientais, o mesmo deve ser utilizado e manejado adequadamente, evitando sua degradação e impactos ao ambiente, bem como mantê-lo adequado para geração de renda. Nesse sentido, objetivou-se 
avaliar a capacidade de uso e a aptidão agrícola das terras em propriedades rurais localizadas na Bacia Hidrográfica do Arroio Pelotas.

\section{MATERIAL E MÉTODOS}

As áreas de estudo compreenderam propriedades rurais localizadas na bacia hidrográfica do Arroio Pelotas, no contexto do município de Pelotas, Rio Grande do Sul. A bacia hidrográfica em questão abrange os municípios de Pelotas, Canguçu, Morro Redondo e Arroio do Padre, com maior abrangência no município de Pelotas e com sua nascente no município de Canguçu (Figura 1). Foram avaliadas nove propriedades rurais com diferentes usos, localizadas no município de Pelotas (Figura 2).

A

\section{MAPA DO BRASIL}

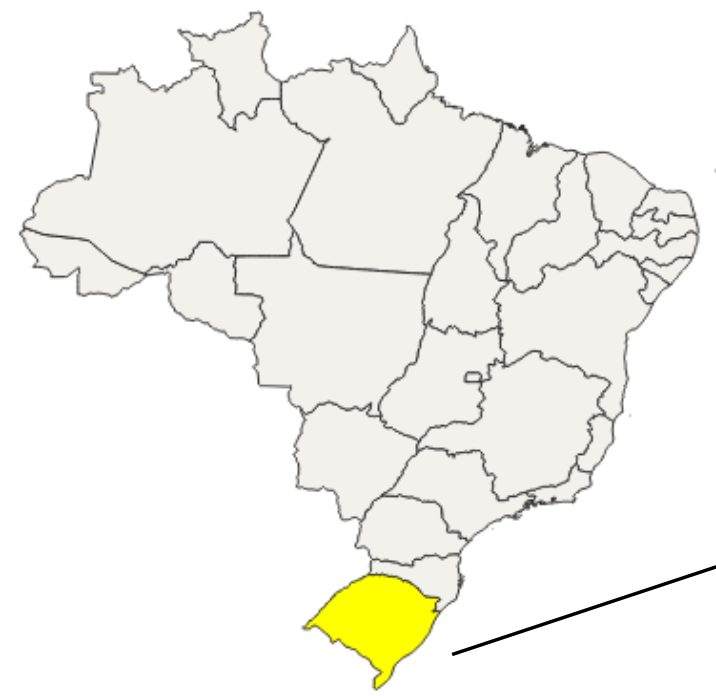

B

\section{MAPA DO RIO GRANDE DO SUL}

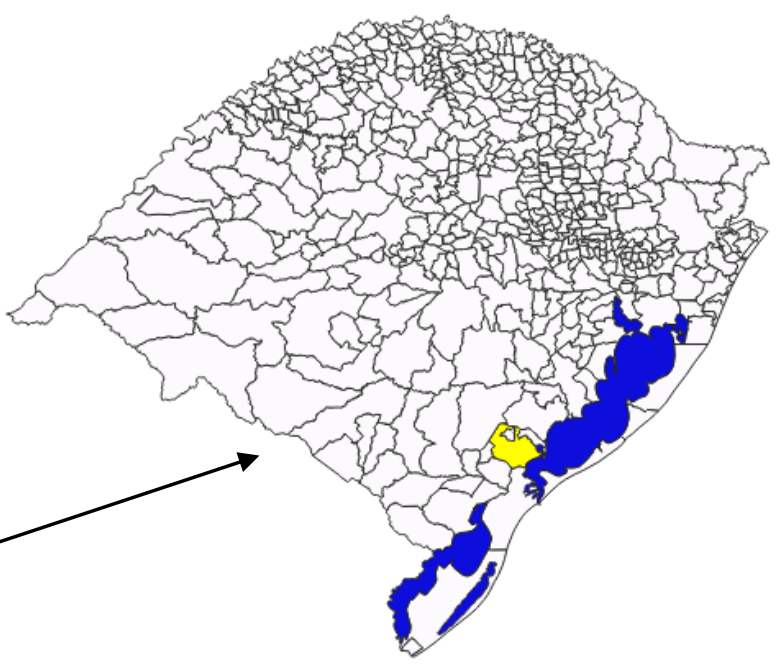

C 
MAPA DE LOCALIZAÇÃO DE PONTOS DE COLETA NA BACIA HIDROGRÁFICA DO ARROIO PELOTAS/ RS/ BRASIL
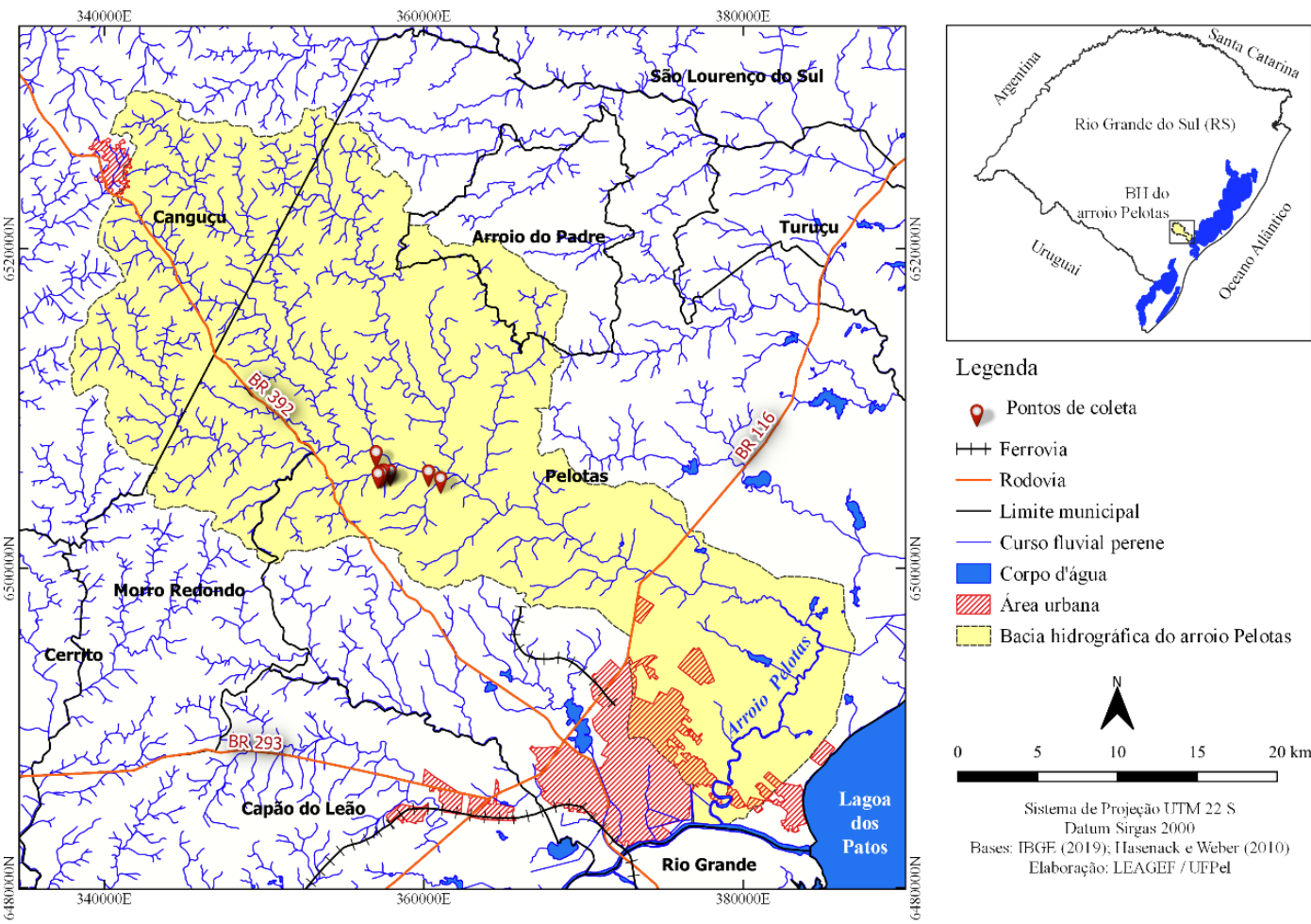

Legenda

Q. Pontos de coleta

H Ferrovia

- Rodovia

— Limite municipal

- Curso fluvial perene

Corpo d'água

WIISA Área urbana

B-.- Bacia hidrográfica do arroio Pelotas

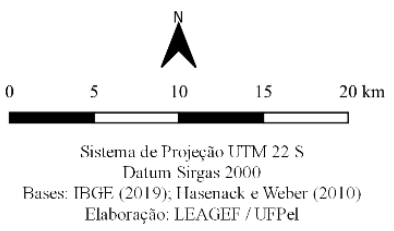

Figura 1 - A) Mapa do Brasil, com o Estado do Rio Grande do Sul em destaque; B) mapa do Estrado do Rio Grande do Sul, com o município de Pelotas em destaque (cor amarela); C) mapa da bacia hidrográfica do Arroio Pelotas e localização das propriedades rurais em estudo Fonte: Autores (2021).

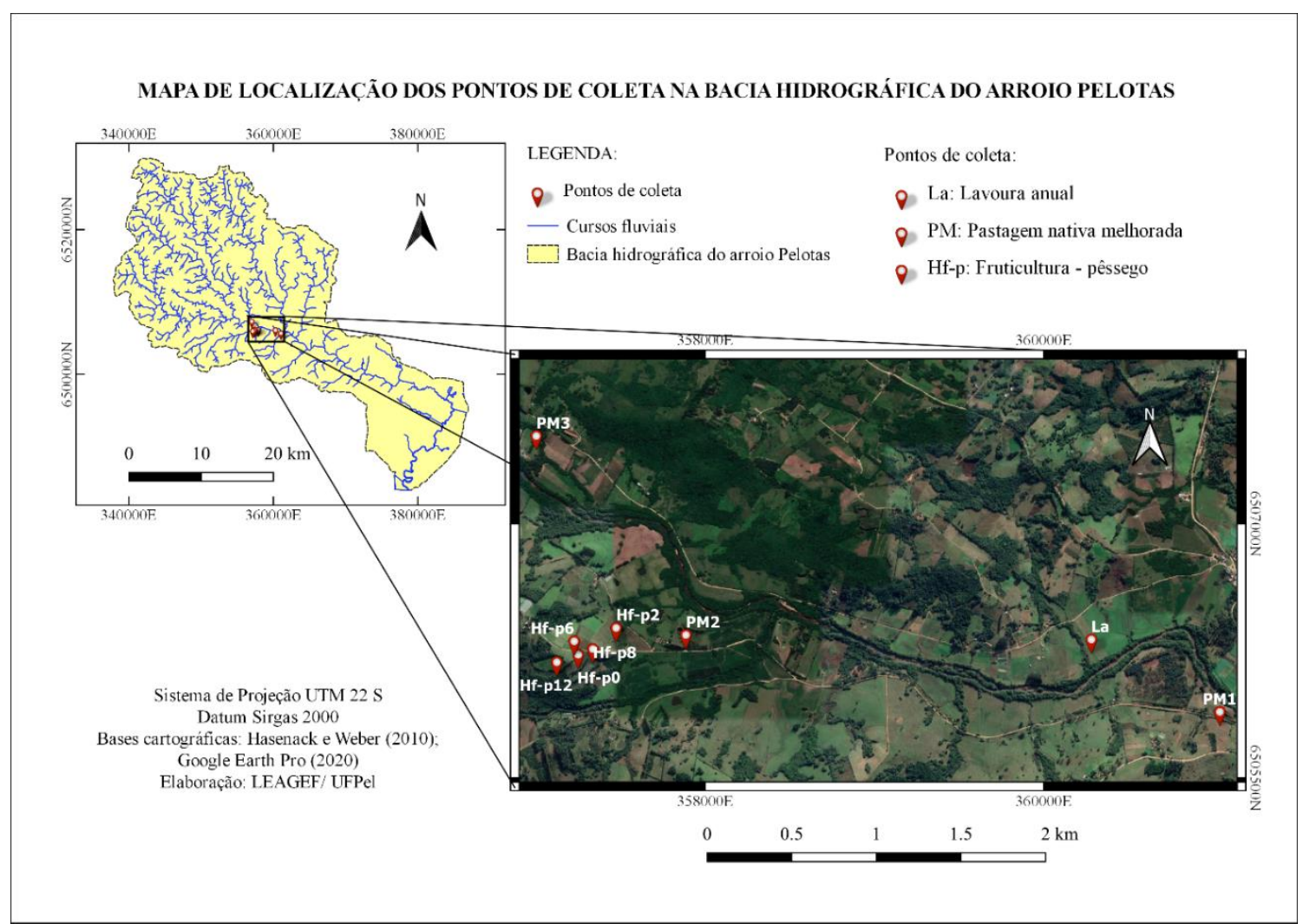

Figura 2 - Mapa de localização das propriedades rurais utilizadas no presente estudo e seus usos do solo Fonte: Autores (2021). 
O clima da região, segundo a classificação climática de Köppen, é do tipo Cfa. De acordo com a Estação Agroclimatológica de Pelotas, considerando as normais climatológicas para o período de 1971-2000 (EMBRAPA/UFPEL/INMET, s.d.), a temperatura média anual é de $17,8^{\circ} \mathrm{C}$, sendo janeiro o mês mais quente, $\operatorname{com} 23,2^{\circ} \mathrm{C}$, e julho o mês mais frio, com $12,3^{\circ} \mathrm{C}$, a precipitação pluviométrica anual é de $1.366,9 \mathrm{~mm}$.

Com base em Streck et al. (2002), na região onde foi realizado o presente estudo, há presença dos solos Neossolos, Chernossolos, Argissolos, Cambissolos, Plintossolos, Planossolos e Gleissolos.

A Figura 3 apresenta imagens dos solos presentes nas propriedades rurais.

A

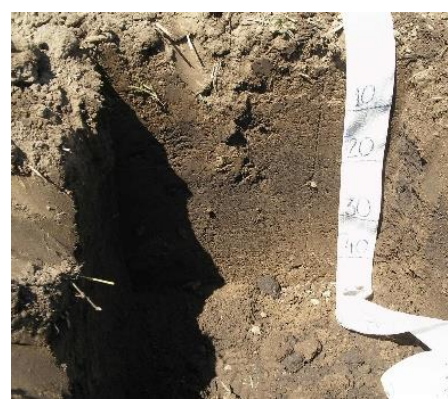

D
B

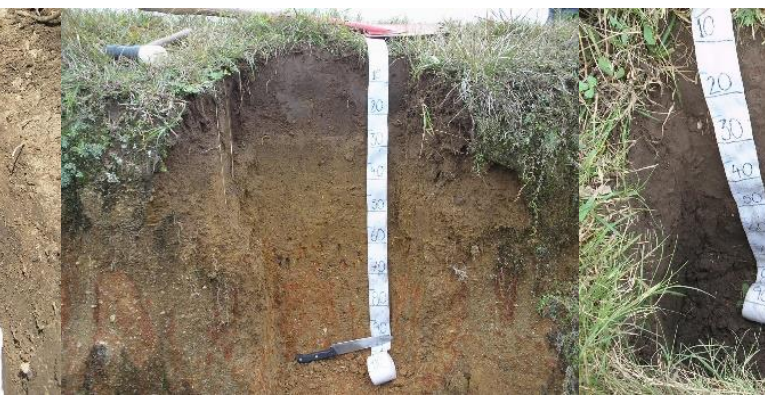

$\mathbf{E}$
C

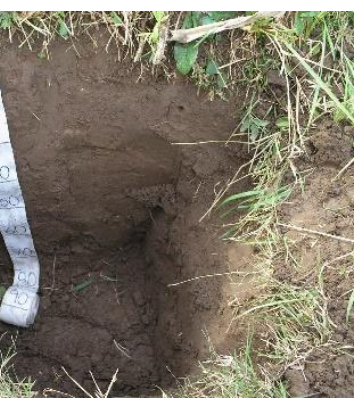

$\mathbf{F}$

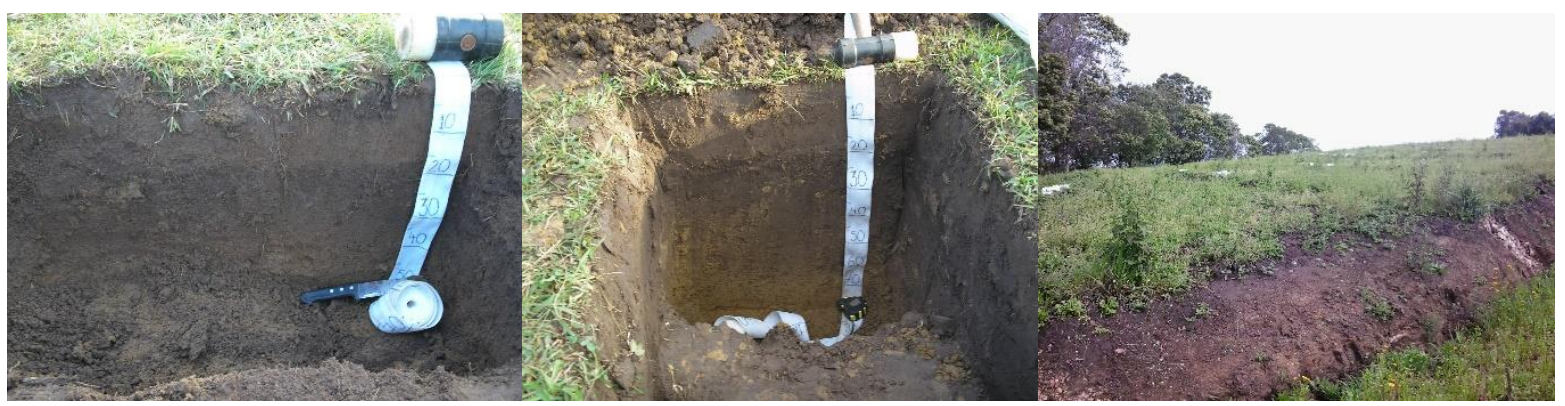

Figura 3 - Imagens dos solos presentes nas propriedades rurais, nos seguintes usos em estudo: A) lavoura; B e C) pastagem 1 (respectivamente terços superior e inferior); D e E) pastagem 2 (respectivamente terços superior e inferior); F) Pomar de pêssego

Fonte: Autores (2021).

Os locais de amostragem nas propriedades rurais foram definidos com auxílio de imagens de satélite e cartas topográficas, além de visitas in situ.

Foram selecionadas uma área de lavoura com o solo revolvido e três áreas de pastagens, por apresentarem relevo ondulado ou suave ondulado, estarem próximas ao Arroio Pelotas e, por utilizarem a área com finalidade econômica. Nas áreas de pastagem, devido a possibilidade de haver diferentes solos ao longo da encosta do relevo, por este ser mais íngreme, as avaliações foram feitas em topossequência, separando em terço superior, médio e inferior. 
Nestas propriedades rurais as avaliações de capacidade de uso e aptidão agrícola das terras foram realizadas em janeiro e fevereiro de 2014. Maiores detalhes sobre as propriedades e glebas utilizadas no presente estudo podem ser obtidas em Silveira (2015).

Representando a fruticultura, foram selecionadas cinco propriedades rurais com pomares de pêssego com diferentes tempos (0, 2, 6, 8 e 12 anos) de implantação. As avaliações foram feitas nas entrelinhas do pomar.

As avaliações da capacidade de uso e aptidão agrícola das terras nesses pomares foram realizadas entre os meses de junho e setembro de 2015. Maiores informações sobre os pomares utilizados no presente estudo podem ser obtidas em Ramos (2016).

Em cada uma das propriedades, foi realizada in situ a classificação de cada gleba, de acordo com sua capacidade de uso, seguindo o "Manual para levantamento utilitário do meio físico e classificação das terras no sistema de capacidade de uso" (LEPSCH et al., 1991) e, a aptidão agrícola das terras, seguindo a metodologia proposta por Schneider, Giasson e Klamt (2007). Algumas avaliações foram feitas em laboratório.

Para a classificação da capacidade de uso (LEPSCH et al., 1991), foram avaliadas as seguintes características:

Textura (a): diferentemente do indicado por Lepsch et al. (1991), onde a textura deve ser avaliada no campo através do tato e da visão, ela foi determinada em laboratório, com metodologia e resultados apresentados em Silveira (2015) e Ramos (2016). A textura pode ser classificada como 0 (não identificado) ou variando entre 1 (textura muito argilosa) e 5 (textura arenosa).

Drenagem (d): foi determinada com base na textura do solo, declividade e cor do perfil de solo. As classes de drenagem podem ser definidas em 0 (não identificada) ou variando entre 1 (excessiva) e 7 (definitivamente impedida).

Pedregosidade e rochosidade (p): foi representada pela presença de material com diâmetro superior a $2 \mathrm{~mm}$. As classes de pedregosidade são constituídas por $\varnothing$-inexistente ou variando entre 1(com poucas pedras) e 9 (solos extremamente rochosos).

Profundidade efetiva $(\mathrm{h})$ : refere-se à profundidade do solo em que as raízes das plantas possam penetrar livremente em busca de água e nutrientes. As classes de profundidade efetiva podem ser classificadas como 0 (não identificada) ou variando entre 1 (muito profundo) e 5 (muito raso).

Declividade (t): determinada com clinômetro tipo Abney Level. As classes de declividade variam entre declives inferiores a 3\% (A) até declives superiores a 75\% (G). 
Erosão hídrica (e): avaliada quanto a erosão laminar ou entressulcos, a erosão em "desbarrancamentos" ou deslizamentos, e a erosão em sulcos, e a deposição dos sedimentos transportados. As classes de erosão hídrica são definidas por:

a) Geral: 0 - presente, mas em grau não identificado; $\varnothing$ - erosão não aparente, tal como ocorre em solos virgens recobertos de vegetação.

b) Erosão laminar ou em entressulcos: 1 - ligeira; 2 - moderada; 3 - severa; 4 - muito severa; 5 - extremamente severa; 6 - áreas desbarrancadas ou translocações de blocos de terra.

c) Erosão em sulcos: quanto à frequência: 7 - ocasionais; 8 - frequentes; 9 - muito frequentes.

Risco de inundação (i): foi discriminada em função de seu risco de ocorrência, ou seja, pela frequência e pela duração usual com que elas ocorrem. A ocorrência de inundação nas áreas foi obtida a partir do histórico de inundação destes locais. As classes de risco de inundação variam de 0 (presente, mas não identificada) até 9 (anuais e longas) ou, inexistente (Ø).

Em seguida foi elaborada uma planilha com as características analisadas e o enquadramento de cada gleba nos grupos e classes que vão até oito, com a intensidade de uso decrescendo da primeira a oitava classe, conforme segue:

Grupo A: terras passíveis de utilização com culturas anuais, perenes, pastagens e/ou reflorestamento e proteção da vida silvestre.

Grupo B: terras impróprias para cultivos intensivos, mas ainda adaptadas para pastagens e/ou reflorestamento e/ou vida silvestre, porém, cultiváveis em casos de algumas culturas especiais protetoras do solo.

Grupo C: terras não adequadas para cultivos anuais, perenes, pastagens ou reflorestamento, porém, apropriadas para a proteção da flora e fauna silvestre, recreação ou armazenamento de água.

Classe I: terras cultiváveis de forma permanente e segura sem limitações ao uso com culturas anuais ou perenes, pastagens e reflorestamento. Os solos são férteis, profundos, com boa retenção de água, sem riscos de inundação e ausência de lençol freático elevado. Não há subclasses na classe I.

Classe II: compreende terras boas, que podem ser cultivadas mediante práticas especiais de conservação.

Classe III: terras que, se cultivadas sem os necessários cuidados, podem sofrer degradação rápida e requerer medidas complexas de conservação para produção de culturas anuais climaticamente adaptadas. 
Classe IV: terras cujas limitações permanentes são muito severas, se utilizadas com culturas anuais. Os solos não são adequados a cultivos intensivos e podem apresentar sérios obstáculos à motomecanização.

Classe V: terras praticamente planas, não adaptadas para culturas anuais comuns em razão de impedimentos como encharcamento e risco frequente de inundação. O solo apresenta poucas limitações para pastagens, silvicultura ou para a cultura do arroz.

Classe VI: terras impróprias para culturas anuais, porém, aptas a culturas permanentes como pastagens, reflorestamentos ou seringueiras e cacau. Para seu uso, faz-se necessário levar em conta que são solos suscetíveis à erosão e, por isso, devem ser observados os processos de proteção e conservação mais indicados para cada caso.

Classe VII: terras que possuem severas limitações permanentes para culturas anuais, inclusive aquelas consideradas protetoras, pastagens e reflorestamentos. São necessários processos conservacionistas intensos para prevenir erosão, mesmo para reflorestamento.

Classe VIII: terras impróprias para cultivo, inclusive as de florestas comerciais ou para produção econômica de qualquer forma de vegetação. São indicadas, apenas, para proteção do meio ambiente e/ou da flora e fauna, preservação permanente, recreação, turismo e para represamento d'água. Podem ser terras encharcadas ou extremamente declivosas, mangues ou terras extremamente pedregosas.

As subclasses são representadas pela natureza das limitações, dentro de cada classe de capacidade de uso, possibilitando assim, que as práticas ou grupo de práticas conservacionistas a serem adotadas sejam mais explícitas. As limitações de uso podem ser de quatro naturezas: e - limitações pela erosão presente e/ou risco de erosão; s - limitações que dizem respeito ao solo; a - limitações por excesso de água; c - limitações climáticas.

A partir das informações disponíveis foi gerada para cada área a fórmula mínima (FM), que é uma representação codificada, na forma de fração, dos parâmetros avaliados e que permite a rápida interpretação das características de cada gleba estudada, conforme a Equação (1).

$$
\mathrm{FM}=\frac{\text { Textura } \frac{\mathrm{A}}{\mathrm{B}} \text { - Drenagem - Ped. e Rochosidade - Prof. Efetiva-Fertilidade }}{\text { Declividade - Erosão - Risco de Inundação }} \text { Uso Atual }
$$

Uso atual: são adotadas notações e convenções para a classificação desta característica de cada gleba de acordo com o uso. Neste trabalho foram avaliadas terras com pastagens (PM), lavoura anual (La) e fruticultura com o cultivo de pêssego (Hf-p).

A fertilidade do solo não foi incorporada na fórmula mínima por não ter sido avaliada. 
Para a aptidão agrícola das terras, seguindo a metodologia proposta por Schneider, Giasson e Klamt (2007), as seguintes avaliações foram realizadas:

Profundidade efetiva do solo (p): indica a espessura máxima do solo até onde as raízes podem alcançar, além disso, determina a tolerância do solo a perda por erosão, sendo que solos mais profundos possuem maior tolerância, enquanto solos menos profundos apresentam menor tolerância. A profundidade pode ser limitada pela presença de camadas rochosas, de linhas de pedra, de gradientes textural abrupto, etc. Pode ser classificada variando entre profundo p1 (maior que $150 \mathrm{~cm}$ ) a raso p4 (menor que $40 \mathrm{~cm}$ ).

Textura $(\mathrm{t})$ e gradiente textural $(\mathrm{g})$ : ela pode ser expressa na forma de classes texturais, utilizando o triângulo textural simplificado ou, generalizadas, baseadas na proporção de argila. A textura foi determinada em laboratório, com metodologia e resultados apresentados em Silveira (2015) e Ramos (2016). As classes texturais do solo, com ausência ou presença de gradiente textural, variam de 11 (argilosa ou muito argilosa no horizonte A / argilosa ou muito argilosa no horizonte B) a t6 (arenosa/arenosa).

Drenagem do solo (h): avaliada através da profundidade do lençol freático e da observação da cor dos horizontes do solo. A presença de cores acinzentadas claras ou escuras normalmente indicam o hidromorfismo, causado pelo excesso de água permanente ou em determinados períodos. As classes de drenagem de cada horizonte podem ser classificadas entre excessivamente drenado h1 (seco na maior parte do ano, inclusive pouco tempo após as chuvas; ausência de lençol freático no perfil) a muito mal drenado h5 (presença de lençol freático e de cores predominantemente acinzentadas, com poucos mosqueados a menos de $30 \mathrm{~cm}$ de profundidade).

Caráter vértico (v): é caracterizado pela presença significativa de argilas expansivas do tipo 2:1 na massa do solo. As características do solo relacionadas ao caráter vértico são classificadas como: sem caráter vértico (v1) ou com caráter vértico (v2).

Declividade (d): foi avaliada com o auxílio de um clinômetro tipo Abney Level. Através da porcentagem de declive do solo é possível determinar a sua classe de declive, variando entre d1 (menor que 3\%) e d6 (maior que 45\%).

Pedregosidade (p): é a proporção de pedras soltas e afloramentos rochosos que ocorrem no perfil ou na superfície do terreno. Indicam a dificuldade de adoção de práticas agrícolas, principalmente com relação a motomecanização e uso de tração animal e, são classificadas como não pedregoso r1 (não há dificuldade de uso de motomecanização) até extremamente pedregoso r4 (as práticas de preparo do solo não são viáveis). 
Degradação (e): refere-se a características superficiais do terreno que podem dificultar ou impedir a adoção de práticas agrícolas, resultado de um manejo inadequado do solo. São observadas as seguintes características: solo compactado; diminuição da infiltração de água; escorrimento superficial da água e perda de solo; formação de sulcos e/ou voçorocas. A classificação é de acordo com as seguintes classes: não degradado ou ligeiramente degradado (e1), moderadamente degradado (e2), muito degradado (e3).

Complexidade do terreno (c): refere-se a características naturais do terreno em termos de declividade, a sua variabilidade de relevo em curtas distâncias, o que pode dificultar ou impedir as práticas agrícolas. Pode ser classificada de acordo com a complexidade do terreno relacionada à dificuldade na adoção das práticas agrícolas: não complexo (c1); moderadamente complexo (c2); muito complexo (c3).

Riscos de inundação (i): refere-se à duração e frequência para as diferentes classes de riscos de inundação. Divididas em não inundável (i1) até inundações frequentes e longas (i5).

Limitações climáticas (a): refere-se às limitações com relação a deficiência de água para as culturas e são deduzidas de acordo com dados de distribuição pluviométrica da região e a capacidade de retenção de água pelo solo. Podem ser classificadas variando de sem deficiência a1 (precipitação anual é superior a $1.800 \mathrm{~mm}$ e bem distribuída) até fortemente deficiente a3 (precipitação anual menor que $1.350 \mathrm{~mm}$ ou entre 1.350 e $1.800 \mathrm{~mm}$ com secas periódicas).

A partir da caracterização da área, a próxima etapa foi a organização dos dados obtidos em campo, em uma tabela, permitindo a identificação das características limitantes, bem como os limites dentro dos quais as classes paramétricas se distribuem.

A classificação das áreas em classes e subclasses segue a orientação a seguir:

Classes de Aptidão: C (culturas anuais de inverno ou de verão), C* (culturas anuais de verão), C** (culturas de verão de ciclo curto), A (arroz irrigado), P (pastagem), S (silvicultura ou fruticultura), R (reflorestamento ou florestamento).

Subclasses de Aptidão: 1 (preparo reduzido com 30\% de cobertura; espécies recuperadoras um ciclo a cada três), 2 (preparo reduzido com $50 \%$ de cobertura; espécies recuperadoras um ciclo a cada dois; faixas de retenção), 3 (plantio direto de espécies densas; faixas de retenção), 4 (fechamentos de sulcos e de voçorocas seguido de dois anos de cultivo de espécies recuperadoras; após utilizar como C3), 5 (controle do pastejo e do trânsito de animais).

A fórmula mínima (FM), de acordo com a metodologia proposta por Schneider, Giasson e Klamt (2007), segue a estruturação apresentada na Equação (2): 


$$
\mathrm{FM}=\text { Classe e Subclasse } \frac{\text { Declividade Drenagem }}{\text { Textura }} \text { Tipo de solo }
$$

\section{RESULTADOS E DISCUSSÃO}

\subsection{Classificação da capacidade de uso das terras: metodologia proposta por Lepsch $e t$ al. (1991)}

$\mathrm{Na}$ Tabela 1 é apresentada a fórmula mínima das áreas avaliadas, que permite a rápida interpretação das características apresentadas no quadro-guia.

Tabela 1 - Fórmula mínima obtida de acordo com os dados levantados no quadro-guia para classificação da capacidade de uso das terras, pela metodologia proposta por Lepsch et al. (1991)

\begin{tabular}{|c|c|c|c|}
\hline Uso atual & Terço da encosta & Altitude, m & **Fórmula Mínima \\
\hline Lavoura & $*$ & 53 & $\frac{3 / 3-3-\varnothing-4}{\mathrm{~B}-0-0} \mathrm{La}$ \\
\hline \multirow[t]{3}{*}{ Pastagem 1} & Superior & 55 & $\frac{3 / 2-2-\varnothing-4}{D-0-\varnothing} \mathrm{PM}$ \\
\hline & Médio & 50 & $\frac{3 / 2-2-\varnothing-5}{C-0-\varnothing} \mathrm{PM}$ \\
\hline & Inferior & 34 & $\frac{3 / 4-3-\varnothing-4}{B-0-0} \mathrm{PM}$ \\
\hline Pastagem2 & Superior, médio & 65,51 & $\frac{3 / 2-2-\varnothing-5}{\mathrm{C}-0-\varnothing} \mathrm{PM}$ \\
\hline \multirow{3}{*}{ Pastagem 3} & Inferior & 28 & $\frac{3 / 3-3-\varnothing-4}{C-0-0} \mathrm{PM}$ \\
\hline & Superior e médio & 79,60 & $\frac{3 / 3-2-\varnothing-4}{\mathrm{C}-0-\varnothing} \mathrm{PM}$ \\
\hline & Inferior & 49 & $\frac{3 / 5-3-\varnothing-4}{B-0-0} \mathrm{PM}$ \\
\hline Pêssego 0, 12 anos & $*$ & 171,127 & $\frac{3 / 3-2-\varnothing-4}{D-0-\varnothing} \mathrm{Hf}-\mathrm{p}$ \\
\hline Pêssego 2, 6 anos & $*$ & 97,107 & $\frac{3 / 3-2-2-5}{D-0-\varnothing} \mathrm{Hf}-\mathrm{p}$ \\
\hline Pêssego 8 anos & $*$ & 79 & $\frac{3 / 3-2-1-4}{D-0-\varnothing} \mathrm{Hf}-\mathrm{p}$ \\
\hline
\end{tabular}

*Por não considerar a possibilidade de diferentes solos na área avaliada, esta não foi separada em terços ou glebas. **Fórmula mínima: $\mathrm{FM}=\frac{\text { Textura } \frac{\mathrm{A}}{\mathrm{B}} \text { - Drenagem - Ped. e Rochosidade - Prof. Efetiva }}{\text { Declividade - Erosão - Risco de Inundação }}$ Uso Atual. La: lavoura anual; PM: pastagem nativa melhorada (PM);Hf - p: fruticultura - pêssego Fonte: Autores (2021).

Todas as áreas apresentaram textura média (3) na camada superficial e, a maioria das áreas, também em subsuperfície. Nas áreas de pastagem 1 e 2 (terço superior e médio), houve 
horizonte subsuperficial com textura argilosa (2), mostrando o gradiente textural do perfil, e no terço inferior da pastagem 1 e 3, respectivamente textura siltosa (4) e arenosa (5) (Figura 4).

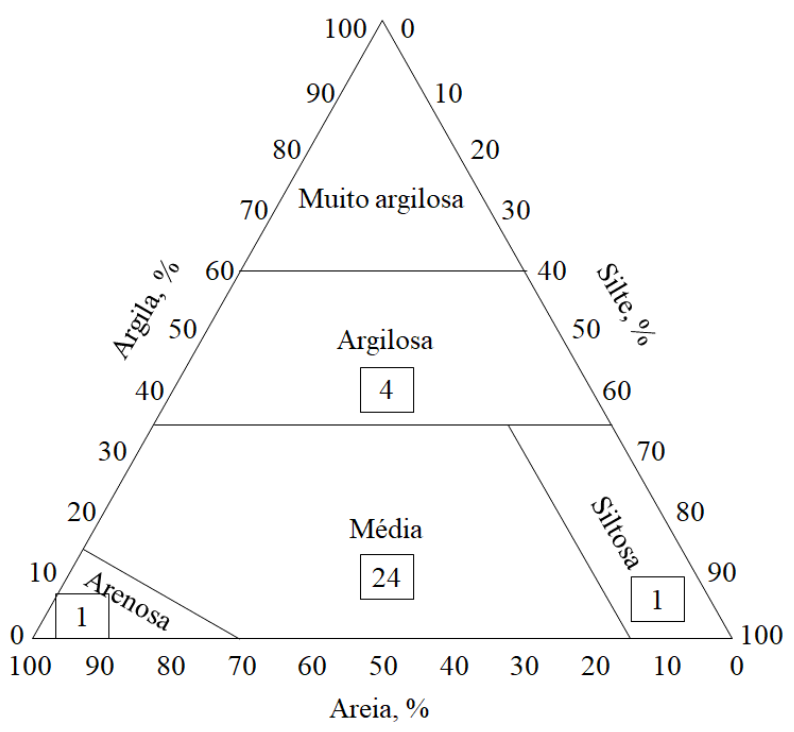

Figura 4 - Triângulo textural simplificado com o número de observações em cada classe textural Fonte: Autores (2021).

A drenagem na maioria das áreas foi adequada (2), mas também houve a ocorrência de drenagem ligeiramente deficiente (3) nas três áreas de pastagem localizadas no terço inferior da encosta e, na área de lavoura. Nestes casos, a drenagem ligeiramente deficiente (3) pode estar condicionada às relativas baixas declividades, altitudes e proximidades dessas áreas do talvegue fluvial, podendo sofrer influência do lençol freático, evidenciada pelas cores mosqueadas no horizonte subsuperficial dos perfis do terço inferior da encosta (Figura 3).

Não houve presença de material com diâmetro superior a $2 \mathrm{~mm}$ (pedregosidade e rochosidade $=\varnothing$ ) nas áreas de lavoura, pastagem e pêssego com 0 e 12 anos, enquanto no pêssego com 2 e 6 anos o solo foi abundante em pedras (2) e, no pêssego com 8 anos, o solo apresentou poucas pedras (1), mas em nenhuma situação impedem a mecanização da área.

A profundidade efetiva do solo, onde as raízes das plantas podem penetrar livremente em busca de água e elementos nutritivos, apresentou-se como raso (4) e muito raso (5). Especialmente para as áreas com pêssego, a retirada de solo da entrelinha para confecção do camaleão na linha de plantio na época de implantação dos pomares, faz com que a profundidade do solo em parte da entrelinha seja reduzida, porém, o camaleão apresenta uma maior profundidade e solo com uma estrutura que possibilita o desenvolvimento radicular do pêssego.

Em relação à declividade, a área de lavoura e o terço inferior da pastagem 1 e 3 tiveram entre 3 a 6\% (B) de declive, 12 a 25\% (D) para as áreas com pêssego e, declives de 6 a 12\% (C) para as demais áreas com pastagem. Para as áreas muito inclinadas, Lepsch et al. (1991) 
indicam que estes são solos muito facilmente erodíveis e, deveriam ser utilizados para cultivos perenes, pastagens ou reflorestamentos, como é o caso apresentado neste estudo. Embora o declive na área de lavoura seja suave, com baixo risco para a erosão hídrica, o revolvimento do solo para implantação de culturas, a textura média da sua camada superficial e a ausência de cobertura vegetal, especialmente após o revolvimento e anterior a implantação de culturas, facilita a ação da chuva desagregando o solo e seu escoamento superficial. Segundo Lepsch et al. (1991), nas áreas menos inclinadas a erosão hídrica comumente apresenta poucos problemas ou pode ser controlada com práticas simples, todavia, quando cultivadas intensamente requerem práticas mais complexas de conservação do solo, como a construção de terraços e o controle de voçorocas, por exemplo.

A erosão esteve presente, mas em grau não identificado (0) nas áreas. Especialmente para a área de lavoura com o solo revolvido, o uso intensivo do solo com aração e gradagem pode acelerar o processo erosivo, conforme verificado por Guadagnin et al. (2005), Zhou et al. (2009) e Suzuki et al. (2012). A erosão hídrica pouco significativa nos pomares de pêssego pode estar associada ao não revolvimento do solo e manutenção das plantas espontâneas ou plantas de cobertura nas entrelinhas, bem como o aporte dos galhos das podas nas entrelinhas. Wade e Sanchez (1983) observaram que o uso de plantas de cobertura foi eficiente no controle da erosão e, além disso, contribui na renovação e manutenção dos nutrientes do solo, podendo ainda aumentar a capacidade de armazenamento de água no solo.

Com exceção da área de lavoura e do terço inferior das áreas sob pastagem, onde o risco de inundação foi considerado presente (0), nas demais áreas esse risco não existe (Ø). Nas áreas de pastagem, há alguns anos foi observada a inundação do terço inferior com a elevação do nível de água do Arroio Pelotas. Especialmente para as áreas de pêssego, o risco de inundação é praticamente inexistente por estarem localizadas em uma cota mais elevada e distante de qualquer canal fluvial.

Por meio das características levantadas in situ e no laboratório e, considerando seus fatores limitantes, cada área foi classificada em grupos (Tabela 2), que apresenta o grupo A como terras passíveis de utilização com culturas anuais, perenes, pastagens e/ou reflorestamento e vida silvestre. A partir do grupo, tem-se as classes possíveis I, II, III e IV. 
Tabela 2 - Grupo, classes e subclasses de capacidade de uso das terras das áreas com lavoura, pastagem e pêssego, pela metodologia proposta por Lepsch et al. (1991)

\begin{tabular}{|c|c|c|c|c|}
\hline Uso do solo & Terço da encosta & Grupo & Classe & Subclasse \\
\hline Lavoura & $*$ & & II & $\mathrm{S}$ \\
\hline Pastagem 1 e 3 & Superior, médio & & III & es \\
\hline Pastagem 1 e 3 & Inferior & A & II & s \\
\hline Pastagem 2 & Superior, médio, inferior & & III & es \\
\hline Pêssego $0,2,6,8$ e 12 anos & $*$ & & III & es \\
\hline
\end{tabular}

A área de lavoura com o solo revolvido e o terço inferior das áreas sob pastagem 1 e 3, foram classificadas na classe II, que compreendem terras boas, que podem ser cultivadas mediante práticas especiais de conservação, especialmente com relação ao solo, por possuírem solos rasos e a textura média na superfície, indicando-se a permanência destas áreas com pastagem ou, no caso da área de lavoura, redução do revolvimento do solo. A subclasse destas propriedades é representada pela letra s - limitações que dizem respeito ao solo.

As demais áreas foram classificadas na classe III, são terras que, se cultivadas sem os necessários cuidados, podem sofrer degradação rápida e requerem medidas complexas de conservação para produção de culturas anuais climaticamente adaptadas. As subclasses foram representadas pelas letras e - limitações pela erosão presente e/ou risco de erosão; s - limitações que dizem respeito ao solo. Essas propriedades, além de apresentarem o fator limitante solos rasos ou muito rasos, ainda possuem elevada declividade.

As áreas estudadas apresentam em comum, como principal fator limitante, a profundidade efetiva do solo, que foi de raso a muito raso. Embora a declividade seja um fator limitante, especialmente nas áreas sob pastagem e nos pomares de pêssego, estes usos fazem com que o risco de erosão hídrica seja reduzido.

\subsection{Classificação da aptidão agrícola das terras: metodologia proposta por Schneider, Giasson e Klamt (2007)}

Pela fórmula mínima (Tabela 3), as classes e subclasses de aptidão agrícola representadas nas áreas foram culturas anuais de verão com preparo reduzido, com $30 \%$ de cobertura; espécies recuperadoras um ciclo a cada três $\left(\mathrm{C}^{*} 1\right)$; pastagem com controle do pastejo e do trânsito de animais (P5); fruticultura com plantio direto de espécies densas; faixas de 
retenção (S3). Como não foi feita a classificação do solo, a classe de solo não foi incorporada na fórmula mínima.

Tabela 3 - Fórmula mínima obtida de acordo com os dados levantados no quadro-guia para classificação da aptidão agrícola das terras das áreas com lavoura, pastagem e pêssego, pela metodologia proposta por Schneider, Giasson e Klamt (2007)

\begin{tabular}{ccc}
\hline Uso do solo & Terço da encosta & $* *$ Fórmula Mínima \\
\hline Lavoura & $*$ & $\mathrm{C} * 1 \frac{\mathrm{d} 2 \mathrm{~h} 3}{\mathrm{t} 2}$ \\
\hline Pastagem 1 & Médio & $\mathrm{P} 5 \frac{\mathrm{d} 4 \mathrm{~h} 2}{\mathrm{t} 3}$ \\
Pastagem 2 & Superiorior e médio & $\mathrm{P} 5 \frac{\mathrm{d} 3 \mathrm{~h} 2}{\mathrm{t} 3}$ \\
\hline Pastagem 3 & Inferior & $\mathrm{P} 5 \frac{\mathrm{d} 2 \mathrm{~h} 3}{\mathrm{t} 2}$ \\
\hline Pêssego 0 ano & Superior e médio & $\mathrm{P} 5 \frac{\mathrm{d} 3 \mathrm{~h} 3}{\mathrm{t} 2}$ \\
Pêssego 2 anos & Inferior & $\mathrm{P} 5 \frac{\mathrm{d} 3 \mathrm{~h} 2}{\mathrm{t} 2}$ \\
Pêssego 6, 8 e 12 anos & $*$ & $\mathrm{P} 5 \frac{\mathrm{d} 2 \mathrm{~h} 3}{\mathrm{t} 2}$ \\
\hline
\end{tabular}

*Por não considerar a possibilidade de diferentes solos na área avaliada, esta não foi separada em terços ou glebas

** Fórmula mínima: FM $=$ Classe e Subclasse $\frac{\text { Declividade Drenagem }}{\text { Textura }}$

Fonte: Autores (2021)

Para as áreas de pastagem, houve predomínio de declividade entre 8\% e 15\% (d3), com menores declives - 3 a $8 \%$ (d2), na área de lavoura e no terço inferior da pastagem 1 e 3, enquanto as áreas com pêssego e o terço superior da pastagem 1 apresentaram declividade mais acentuada, entre 15\% e 25\% (d4). Selby (1973) verificou que a precipitação máxima ocorrida em uma hora, o ângulo de inclinação, a precipitação total e o tamanho de partículas explicaram, juntos, $61 \%$ do escoamento superficial em áreas não utilizadas.

Com exceção da área de lavoura e do terço inferior das áreas sob pastagem, onde o solo foi considerado moderadamente drenado (h3), as demais áreas apresentam boa drenagem, com lençol freático ausente no perfil (h2).

A classe textural dos horizontes A/B foi de média/média (t2) e média/argilosa (t3), mostrando o gradiente textural em $\mathrm{t} 3$. 
Avaliando a capacidade de uso e a aptidão agrícola de uma fazenda em São Domingos do Araguaia/PA, França et al. (2019) identificaram que o baixo potencial de uso agrícola da área deveu-se à presença de solos arenosos, associado à sua baixa saturação por bases, baixa disponibilidade de água e alta suscetibilidade à erosão. Por outro lado, estudando a capacidade de uso das terras da Serra da Jiboia/BA, Cassamo et al. (2019) constataram que as limitações para a prática de atividades agropecuárias deram-se aos relevos com declives acentuados, e ao solo com pequena profundidade efetiva, baixo teor de nutrientes, acidez elevada e/ou alta saturação por alumínio.

Em relação às limitações agrícolas (Tabela 4), a profundidade efetiva variou de pouco profundo (p3) a raso (p4). Cabe salientar que a profundidade efetiva aqui refere-se a camada favorável ao desenvolvimento das raízes das plantas, e não à profundidade efetiva do perfil do solo.

Tabela 4 - Classificação das limitações agrícolas a partir de algumas características indicadas na metodologia para classificação da aptidão agrícola das terras (Schneider, Giasson e Klamt, 2007)

\begin{tabular}{lcccc}
\hline \multicolumn{1}{c}{ Uso do solo } & $\begin{array}{c}\text { Profundidade } \\
\text { efetiva }\end{array}$ & $\begin{array}{c}\text { Complexidade } \\
\text { do terreno }\end{array}$ & Pedregosidade & Degradação \\
\hline Lavoura & $\mathrm{p} 3$ & $\mathrm{c} 1$ & $\mathrm{r} 1$ & $\mathrm{e} 1$ \\
Pastagem 1 & $\mathrm{p} 3$ & $\mathrm{c} 1$ & $\mathrm{r} 1$ & $\mathrm{e} 1$ \\
(terço superior e inferior) & $\mathrm{p} 4$ & $\mathrm{c} 1$ & $\mathrm{r} 1$ & $\mathrm{e} 1$ \\
Pastagem 1 (terço médio) & $\mathrm{p} 4$ & $\mathrm{c} 1$ & $\mathrm{r} 1$ & $\mathrm{e} 1$ \\
Pastagem 2 & $\mathrm{p} 3$ & $\mathrm{c} 1$ & $\mathrm{r} 1$ & $\mathrm{e} 1$ \\
(terço superior e médio) & $\mathrm{p} 3$ & $\mathrm{c} 1$ & $\mathrm{r} 1$ & $\mathrm{e} 1$ \\
Pastagem 2 (terço inferior) & $\mathrm{p} 3$ & $\mathrm{c} 1$ & $\mathrm{r} 1$ & $\mathrm{e} 1$ \\
Pastagem 3 & $\mathrm{p} 4$ & $\mathrm{c} 1$ & $\mathrm{r} 1$ & $\mathrm{e} 1$ \\
Pêssego 0, 8, 12 anos & Fonte: Autores $(2021)$. & & \\
Pêssego 2, 6 anos & &
\end{tabular}

As áreas apresentaram terreno não complexo (c1), não pedregoso $(\mathrm{r} 1)$, onde não há dificuldade de uso de motomecanização, e não degradada ou ligeiramente degradada(e1). Embora algumas áreas de pêssego tenham cascalho presente no solo, ele não limita a mecanização.

Pode-se considerar o risco de inundação como ocasionais e curtas (i2) para a área de lavoura e o terço inferior das áreas sob pastagem, enquanto as demais áreas são consideradas não inundáveis (i1) devido a localização em cota relativamente elevada.

Os solos não apresentaram caráter vértico (v1) e a limitação climática foi moderadamente deficiente, com precipitação anual entre 1.350 e $1.800 \mathrm{~mm}$, com secas ocasionais (a2). 


\subsection{Recomendações de práticas conservacionistas e possibilidades de estudos e ações futuras}

A partir das limitações indicadas pela classificação da capacidade de uso e da aptidão agrícola das terras, são apontadas algumas recomendações gerais de práticas conservacionistas a serem implementadas ou mantidas nas áreas.

Algumas práticas são indicações comuns a todas as áreas: evitar o trânsito de máquinas ou animais com o solo muito úmido, evitando a compactação adicional do solo; realizar a correção da fertilidade do solo de acordo com o laudo de análise de solo.

Para a área de lavoura, algumas práticas específicas são recomendadas como: evitar ou minimizar o revolvimento do solo, implementando o cultivo mínimo ou semeadura direta; utilizar plantas de cobertura e fazer rotação de culturas.

Nas áreas de pastagem, recomenda-se utilizar uma taxa de lotação animal adequada e o pastoreio controlado para manter uma cobertura vegetal mínima sobre o solo e, evitar a sua compactação e reduzir o risco de erosão; continuar a não queimada da pastagem; construção de terraços.

Para os pomares de pêssego, indica-se a continuidade do uso de plantas de cobertura, preferencialmente, ou manter a vegetação espontânea na entrelinha, minimizando a evaporação da água do solo e a compactação, e reduzindo o risco de erosão; continuar praticando a disposição das podas do pessegueiro na entrelinha de plantio; evitar o revolvimento do solo, prática que já vem sendo adotada nas propriedades.

Tendo como base as recomendações de práticas conservacionistas, estudos e ações posteriores podem ser realizados como: verificar a umidade adequada para o trânsito de máquinas e animais, a fim de evitar a compactação adicional do solo; elevar os níveis de fertilidade do solo, de acordo com o laudo de análise; identificar plantas de cobertura que forneçam maior aporte de biomassa e ciclagem de nutrientes, e que possam fazer parte de um sistema de rotação de culturas para as lavouras anuais, e seu uso na entrelinha para os pomares de pêssego; verificar a taxa de lotação animal adequada para manter uma cobertura vegetal mínima sobre o solo e evitar a sua compactação adicional e reduzir o risco de erosão; estimular a construção de terraços nas propriedades rurais componentes da bacia hidrográfica.

\section{CONCLUSÕES}


Este trabalho, referente à capacidade de uso e aptidão agrícola de propriedades rurais localizadas na zona rural do município de Pelotas/RS, traz para discussão a necessidade de adoção de práticas de conservação do solo e da água, para manutenção da capacidade produtiva do solo e dos processos ambientais e, evitar ou minimizar sua degradação e do ambiente. Seus resultados servem como base para agricultores, extensionistas e gestores, para implementação de práticas conservacionistas, especialmente a nível de bacia hidrográfica.

De modo geral, as áreas apresentam limitações quanto a capacidade de uso e aptidão agrícola, especialmente a pouca profundidade efetiva do solo e o risco de erosão, associado a declividade e a textura média na camada superficial do solo.

Apesar das limitações quanto ao uso destas áreas, a pastagem e a fruticultura são usos menos intensos de exploração do solo do que as culturas anuais, contudo, ainda se tornam necessárias a implementação de novas práticas conservacionistas do solo e da água ou manutenção daquelas já utilizadas.

As metodologias de avaliação da capacidade de uso e da aptidão agrícola das terras utilizadas no estudo se mostram satisfatórias no sentido de diagnosticar a intensidade do uso, as características das propriedades e as limitações de uso.

Sugere-se a aplicação destas metodologias em outras propriedades rurais da bacia hidrográfica do Arroio Pelotas, de modo a se obter um panorama mais abrangente sobre os usos na bacia e, desta forma, contribuir para o manejo da bacia hidrográfica. Aliado a isto, outros estudos podem estar associados como, qualidade do solo e da água na bacia, processos erosivos e produção de sedimentos.

\section{AGRADECIMENTOS}

Aos agricultores que possibilitaram a realização deste estudo em suas propriedades.

\section{REFERÊNCIAS}

CASSAMO, M. J. et al. Capacidade de uso das terras da Serra da Jiboia - Bahia. Revista Brasileira de Geografia, Rio de Janeiro, v. 64, n. 2, p. 18-36, 2019.

COMPANHIA ESTADUAL DE ENERGIA ELÉTRICA - GERAÇÃO E TRANSMISSÃO. Planos de uso e ocupação do solo no entorno dos reservatórios das usinas hidrelétricas da CEEE-GT. s.d. Disponível em: http://www.ceee.com.br/pportal/ceee/Component/Controller.aspx?CC=29417. Acesso em: 26 jun. 2016. 
CUNHA, C. M. L. da; PINTON, L. G. Avaliação da capacidade de uso da terra da bacia do córrego do cavalheiro - Analândia, SP. Geociências, São Paulo, v. 31, n. 3, p. 459-471, 2012.

D'AGOSTINI, L. R.; SCHLINDWEIN, S. L. Dialética da avaliação do uso e manejo das terras: da classificação interpretativa a um indicador de sustentabilidade. Florianópolis: UFSC, 1998. 170 p.

EMPRESA BRASILEIRA DE PESQUISA AGROPECUÁRIA - EMBRAPA. UNIVERSIDADE FEDERAL DE PELOTAS - UFPEL. INSTITUO NACIONAL DE METEOROLOGIA - INMET. Normais climatológicas período: 1971/2000 (mensal/anual). Disponível em: http://agromet.cpact.embrapa.br/estacao/mensal.html. Acesso em: 02 jun. 2020.

FRANÇA, B. B. da et al. Capacidade de uso e aptidão agrícola de uma fazenda em São Domingos do Araguaia (PA). Revista Geonorte, Manaus, v. 10, n.36, p. 134-153, 2019.

GUADAGNIN, J. C. et al. Perdas de solo, água e nitrogênio por erosão hídrica em diferentes sistemas de manejo. Revista Brasileira de Ciência do Solo, Viçosa, v. 29, n. 2, p. 277-286, 2005.

LEPSCH, I. F. et al. Manual para levantamento utilitário do meio físico e classificação de terras no sistema de capacidade de uso. Campinas: SBCS, 1991. 175 p.

RAMALHO FILHO, A.; BEEK, K. J. Sistema de avaliação da aptidão agrícola das terras. 3. ed. Rio de Janeiro: EMBRAPA-CNPS, 1995. 65p.

RAMOS, M. F. Variabilidade de características físicas e hídrica do solo em pomares de pêssego com diferentes idades no município de Pelotas - RS. Orientador: Luis Eduardo Akiyoshi Sanches Suzuki. 2016. 90 f. Dissertação (Mestrado em Recursos Hídricos) Universidade Federal de Pelotas, Pelotas, 2016.

SCHNEIDER, P.; GIASSON, E.; KLAMT, E. Classificação da aptidão agrícola das terras: um sistema alternativo. Guaíba: Agrolivros, 2007. 72 p.

SELBY, M. J. An investigation into causes of runoff from a catchment of pumice lithology, in New Zealand. Hydrological Sciences Journal, Wallingford, v. 18, n. 3, p. 255-280, 1973.

SILVEIRA, C. P. L. da. Caracterização de solos e sedimentos em depósitos e fontes em potencial na Bacia Hidrográfica do Arroio Pelotas. Orientador: Luis Eduardo Akiyoshi Sanches Suzuki. 2015. 127 f. Dissertação (Mestrado em Recursos Hídricos) - Universidade Federal de Pelotas, Pelotas, 2015.

STRECK, E. V. et al. Solos do Rio Grande do Sul. Porto Alegre: EMATER/RS - UFRGS, 2002.

SUZUKI, L. E. A. S. et al. Perdas de solo por erosão hídrica e granulometria do material erodido em propriedades agrícolas. In: POLETO, C. et al. (organizadores). X ENES Encontro Nacional de Engenharia de Sedimentos: artigos selecionados, 2012, 10., Porto Alegre. Anais [...]. Porto Alegre: ABRH, 2012. p. 93-108. (ISBN: 978-85-60308-34-7). 
WADE, M. K.; SANCHEZ, P. A. Mulching and green manure applications for continous crop production in the Amazon basin. Agronomy Journal, Madison, v. 75, n. 1, p. 39-45, 1983.

ZHOU, X. et al. Cost-effectiveness and cost-benefit analysis of conservation management practices for sediment reduction in an Iowa agricultural watershed. Journal of Soil and Water Conservation, Ankeny, v. 64, n. 5, p. 314-323, 2009.

\section{DADOS DOS AUTORES}

\section{Luis Eduardo Akiyoshi Sanches Suzuki}

E-mail: dusuzuki@gmail.com

Curriculum Lattes: http://lattes.cnpq.br/8976157511758125

Doutorado em Engenharia Florestal pela Universidade Federal de Santa Maria, mestrado em Ciência do Solo pela Universidade Federal de Santa Maria, graduação em Agronomia pela Universidade Estadual Paulista Júlio de Mesquita Filho e licenciado em Geografia pela Universidade Federal de Pelotas. Atualmente é professor Associado da Universidade Federal de Pelotas. Tem experiência na área de Agronomia, com ênfase em Ciência do Solo, atuando principalmente nos seguintes temas: manejo e conservação do solo e propriedades físicas, hídricas e mecânicas do solo.

\section{William Roger da Silva Almeida}

E-mail: willrogerall@yahoo.com.br

Curriculum Lattes: http://lattes.cnpq.br/5148651874339884

Graduado em Engenharia Hídrica pela Universidade Federal de Pelotas, com experiência na área de Engenharia Civil com ênfase em Engenharia Hídrica.

\section{Rodrigo de Lima do Amaral}

E-mail: rodrigo do amaral@ hotmail.com

Curriculum Lattes: http://lattes.cnpq.br/6738340081204354

Graduado em Engenharia Hídrica pela Universidade Federal de Pelotas, com experiência na área de Engenharia Civil com ênfase em Recursos Hídricos.

\section{Mariana Fernandes Ramos}

E-mail: mariana.fernandesr@gmail.com

Curriculum Lattes: http://lattes.cnpq.br/5990517304996476

Doutorado em Ciência do Solo pela Universidade Federal do Rio Grande do Sul, mestrado em Recursos Hídricos pela Universidade Federal de Pelotas e graduação em Tecnologia em Gestão Ambiental pelo Instituto Federal Sul-Rio-Grandense.

\section{Moisés Ortemar Rehbein}

E-mail: moisesgeoufpel@gmail.com

Curriculum Lattes: http://lattes.cnpq.br/9410223282785441

Doutorado em Geografia Física pela Universidade de São Paulo, mestrado em Geografia/ Análise Ambiental pela Universidade Federal do Rio Grande do Sul/Universidade de São Paulo e graduação em Estudos Sociais/Licenciatura Plena em Geografia pela Universidade de Santa Cruz do Sul e graduação em Geografia/Bacharelado pela Universidade Federal do Rio Grande do Sul. Atualmente é professor Associado do Departamento de Geografia do Instituto de Ciências Humanas da Universidade Federal de Pelotas. Faz parte do corpo docente do Programa 
de Pós-Graduação em Geografia da Universidade Federal de Pelotas. No CNPq, está vinculado ao Grupo de Pesquisa Geomorfologia e Meio Ambiente.

\section{Roberta Jeske Kunde}

E-mail: roberta_kunde@hotmail.com

Curriculum Lattes: http://lattes.cnpq.br/9454790488950880

Doutorado em Agronomia em Sistemas de Produção Agrícola Familiar da Universidade Federal de Pelotas, mestrado em Ciências na área de concentração em Solos pela Universidade Federal de Pelotas e graduação em Química Ambiental pela Universidade Católica de Pelotas. 